\title{
DIVERSIDADE GENÉTICA DE POPULAÇÕES NATURAIS DE DIPTERYX ALATA LOCALIZADAS NOS MUNICÍPIOS DE BRASILÂNDIA/MS, INDIARA/GO E ITARUMÃ/GO ESTIMADA POR MARCADORES MICROSSATÉLITES
}

\author{
Christian Luis Ferreira Berti ${ }^{1}$, Takeshi Kamada ${ }^{2}$, Marcela Aparecida de Moraes ${ }^{3}$, Patricia \\ Ferreira Alves ${ }^{3}$, Alexandre Marques da Silva ${ }^{4}$, Mario Luiz Teixeira de Moraes ${ }^{5}$, Mariana \\ Pina da Silva Berti ${ }^{6}$
}

\footnotetext{
${ }^{1}$ Professor de biologia do IF Goiano - Campus Avançado Catalão e bolsista DCR/FAPEG/CNPq, CatalãoGO, Brasil.

${ }^{2}$ Professor do Departamento de Agronomia da Universidade de Rio Verde, Rio Verde-GO, Brasil.

${ }^{3}$ Doutora em Agronomia pela Universidade Estadual Paulista (UNESP), Faculdade de Engenharia, Câmpus de Ilha Solteira, SP.

5 Geógrafo, Técnico Agropecuário do Departamento de Fitotecnia, Tecnologia de Alimentos e Sócio Economia - Doutorando do Programa de Pós-Graduação em Agronomia da Universidade Estadual Paulista (UNESP), Faculdade de Engenharia, Câmpus de Ilha Solteira, SP.

${ }^{5}$ Prof. Titular do Departamento de Fitotecnia, Tecnologia de Alimentos e Sócio Economia da Universidade Estadual Paulista (UNESP), Faculdade de Engenharia, Câmpus de Ilha Solteira, SP.

${ }^{6}$ Professora de Agronomia da Universidade Estadual de Goias- Campus de Ipameri, Ipameri-GO, Brasil.
}

RESUMO: O Baru (Dipteryx alata Vogel), pertence à família Fabaceae apresenta ampla distribuição no bioma Cerrado e um grande potencial para o uso na culinária local, ornamental e medicinal, sendo um importante recurso genético vegetal. Entretanto seu habitat está sob forte perturbação antrópica e devido a suas utilidades a espécie tem sido muito explorada. Neste contexto, o presente trabalho teve como objetivo avaliar a diversidade genética de três populações naturais de Dipteryx alata Vog, localizadas nos municípios de Brasilândia/MS, Indiara/GO e Itarumã/GO, utilizando marcadores moleculares microssatélites para fins de conservação da espécie. Folhas de acessos de baru de cada localidade foram coletadas e utilizadas para a extração das amostras de DNA genômico e genotipadas utilizando marcadores moleculares microssatélites específico para a espécie. As três populações de Dipteryx alata embora apresentem condições ambientais diferentes, apresentaram diversidade genética semelhante e forte endogamia. Para as pesquisas futuras, seria oportuno aumentar o número de amostras de cada população, coletar sementes e estudar a geração descendente, a fim de ter maior entendimento nos padrões do sistema de reprodução e fluxo gênico para assim, poder estimar e orientar uma coleta de sementes adequada visando à conservação genética ex situ e restauração ambiental.

Palavras-chave: Cerrado. Conservação genética ex situ. Endogamia.

GENETIC DIVERSITY OF NATURAL POPULATIONS OF DIPTERYX ALATA

LOCATED IN THE MUNICIPALITIES OF BRASILÂNDIA / MS, INDIARA / GO AND ITARUMÃ / GO ESTIMATED BY MICROSSATELLITE MARKERS

Cultura Agronômica, Ilha Solteira, v.26, n.2, p.203-216, 2017 


\begin{abstract}
Baru (Dipteryx alata Vogel), belongs to the Fabaceae family, presents a wide distribution in the Cerrado biome and great potential for use in local, ornamental and medicinal cuisine, being an important vegetal genetic resource. However its habitat is under strong anthropic disturbance and due to its uses the species has been very exploited. In this context, the present work had as objective to evaluate the genetic diversity of three natural populations of Dipteryx alata Vog located in the municipalities of Brasilândia/MS, Indiara/GO and Itarumã/GO, using microsatellite markers for conservation purposes of the species. Leaves of baru access from each locality were collected and used for the extraction of genomic DNA samples and genotyped using microsatellite markers specific for the species. The three populations of Dipteryx alata, although presenting different environmental conditions, presented similar genetic diversity, but presented lower levels of genetic diversity than are generally detected in other species and strong inbreeding. For future research, it would be opportune to increase the number of samples from each population, to collect seeds and to study the descendant generation, in order to have a better understanding of the breeding system and gene flow patterns in order to be able to estimate and guide an appropriate seed collection aiming at ex situ genetic conservation and environmental restoration.
\end{abstract}

Key words: Cerrado. Ex situ genetic conservation. Endogamy.

\title{
INTRODUÇÃO
}

O Cerrado possui grande diversidade de plantas, entre as quais muitas apresentam grandes possibilidades de exploração, cujo maior potencial é sua utilidade na alimentação. O barueiro (Dipteryx alata Vogel) pertencente à família Fabaceae faz parte do grupo de espécies nativas usadas pela população regional como fonte complementar de renda familiar, pela exploração extrativista de seu fruto, o baru.

É uma das espécies frutíferas nativas mais promissoras para cultivo está relacionado entre as 110 espécies nativas do Cerrado com maior potencial econômico para a população da, região e entre as 10 mais promissoras para cultivo, devido ao seu potencial alimentício, madeireiro, medicinal, ornamental e forrageiro (ALMEIDA et al., 1998; PEREIRA et al., 2001). Apesar da sua irregularidade na produção de frutos, possui alta produtividade, facilidade no transporte e armazenamento dos frutos e a qualidade do produto. Como alimento, a amêndoa é rica em proteínas, lipídios insaturados, fibras e minerais essenciais. Além disso, é uma espécie-chave, pois amadurece na época da seca, alimentando várias espécies da fauna do Cerrado (SANO et al., 2004; ALMEIDA et al., 1998; RIBEIRO et al., 2000; SANO et al., 2010).

Uma espécie é formada por populações espalhadas por sua área de distribuição geográfica. Essas populações naturais são fonte de germoplasma para programas de melhoramento genético e também são as unidades sobre as quais incide o manejo para a

Cultura Agronômica, Ilha Solteira, v.26, n.2, p.203-216, 2017 
produção ou conservação dos recursos naturais (FALEIRO, 2007; FALEIRO, 2011; HOPKIN, 2004; ROBINSON, 1998).

No campo, as características morfológicas são utilizadas normalmente para descrever e discriminar variedades de plantas (ANTI, 2000), podendo servir para auxiliar a escolha de indivíduos com potencial para diversas finalidades. No entanto, essas características podem ser avaliadas de forma subjetiva e ainda sofrer influências ambientais positivas ou negativas, impossibilitando a detecção de polimorfismo de modo confiável entre espécies, variedades e indivíduos.

Com os avanços da biotecnologia, o advento dos marcadores moleculares possibilitou a discriminação genotípica de forma hábil, pois permite o estudo da variação genética em nível de DNA (FERREIRA; GRATTAPAGLIA, 1998).

Os marcadores moleculares podem ser utilizados como ferramenta para estudos de diversidade genética entre indivíduos, dentro e entre populações ou espécies relacionadas.

Os marcadores microssatélites são ferramenta importante para se estimar parâmetros genéticos de subpopulações mantidas em coleções de germoplasma. Esse tipo de marcador molecular é amplamente utilizado em estudos de diversidade genética neutra e dos padrões de fluxo gênico e parentesco, além de fornecer conhecimento sobre o sistema reprodutivo de uma espécie (GOLDSTEIN; SCHOLOTTER, 1999; SCHOLOTTERER, 2000).

Mesmo com sua extrema importância econômica e ecológica, grandes populações desta espécie foram destruídas e continuam sendo perdidas em ecossistemas nativos (CARVALHO, 2003; POTT; POTT, 2003; SANO et al., 2004). Assim estudos de prémelhoramento e conservação da variabilidade genética tornam-se necessários, a fim de garantir o uso adequado desse recurso genético, bem como auxiliar no controle da estabilidade genética na coleção de germoplasma para subsidiar estratégias eficientes de manutenção e manejo (FALEIRO, 2007).

Dentro do contexto apresentado, objetivou-se neste trabalho estimar a diversidade genética de três populações naturais de Dipteryx alata Vog, localizadas nos municípios de Brasilândia/MS, Indiara/GO e Itarumã/GO, por meio de marcadores moleculares microssatélites.

\section{MATERIAL E MÉTODOS}

\section{Material}

O estudo foi realizado a partir de três populações naturais de Dipteryx alata Vog, localizadas nos municípios de Brasilândia/MS, Indiara/GO e Itarumã/GO (Tabela 1 e 2).

As características dos municípios em que se localizam as populações de D. alata evidenciam diferenças quanto à altitude, vegetação, clima, solo, relevo e pluviosidade, o que é interessante quando se busca quantificar a diversidade genética de uma espécie arbórea.

Cultura Agronômica, Ilha Solteira, v.26, n.2, p.203-216, 2017 
Tabela 1. Coordenadas geográficas das três populações naturais de baru utilizadas neste estudo.

\begin{tabular}{|c|c|c|c|c|c|}
\hline Matriz & Local & Estado & Latitude & Longitude & Altitude \\
\hline 1 & Indiara & $\mathrm{GO}$ & 8096705,81 & 541179,20 & 585,2 \\
\hline 2 & Indiara & GO & 8096653,79 & 541069,81 & 589,1 \\
\hline 3 & Indiara & GO & 8096545,48 & 541291,10 & 595,8 \\
\hline 4 & Indiara & GO & 8096623,01 & 541400,54 & 599,8 \\
\hline 5 & Indiara & GO & 8096675,62 & 541521,73 & 600,0 \\
\hline 6 & Indiara & GO & 8096783,38 & 541421,53 & 599,6 \\
\hline 7 & Indiara & GO & 8096786,76 & 541421,54 & 599,6 \\
\hline 8 & Indiara & GO & 8096870,00 & 541288,80 & 599,4 \\
\hline 9 & Indiara & GO & 8096975,67 & 541306,73 & 601,1 \\
\hline 10 & Indiara & GO & 8097080,21 & 541126,78 & 615,7 \\
\hline 11 & Indiara & GO & 8092041,83 & 602180,51 & 614,7 \\
\hline 12 & Indiara & GO & 8091991,74 & 602056,23 & 616,2 \\
\hline 13 & Indiara & GO & 8092355,57 & 602746,13 & 611,3 \\
\hline 14 & Indiara & GO & 8092434,83 & 601642,03 & 610,2 \\
\hline 15 & Indiara & GO & 8092450,04 & 602539,88 & 611,4 \\
\hline 1 & Brasilândia & MS & 7650897,22 & 393549,79 & 355,3 \\
\hline 2 & Brasilândia & MS & 7650971,21 & 393438,06 & 360,5 \\
\hline 3 & Brasilândia & MS & 7650938,05 & 393342,08 & 363,5 \\
\hline 5 & Brasilândia & MS & 7650874,20 & 393926,14 & 359,7 \\
\hline 6 & Brasilândia & MS & 7651188,05 & 393555,90 & 373,1 \\
\hline 13 & Brasilândia & MS & 7651727,69 & 394138,25 & 356,9 \\
\hline 15 & Brasilândia & MS & 7651662,60 & 394087,72 & 360,3 \\
\hline 18 & Brasilândia & MS & 7651509,22 & 394317,44 & 365,3 \\
\hline 19 & Brasilândia & MS & 7651552,66 & 394427,69 & 366,8 \\
\hline 20 & Brasilândia & MS & 7651656,88 & 394487,94 & 367,3 \\
\hline 21 & Brasilândia & MS & 7651645,16 & 394679,08 & 366,9 \\
\hline 26 & Brasilândia & MS & 7651480,54 & 394866,84 & 357,5 \\
\hline 27 & Brasilândia & MS & 7651451,23 & 394940,19 & 354,6 \\
\hline 28 & Brasilândia & MS & 7651524,10 & 394979,99 & 353,2 \\
\hline 30 & Brasilândia & MS & 7651595,61 & 394944,87 & 359,2 \\
\hline 31 & Brasilândia & MS & 7651575,25 & 394843,19 & 362,4 \\
\hline 32 & Brasilândia & MS & 7651622,34 & 393783,58 & 368,2 \\
\hline 33 & Brasilândia & MS & 7651602,88 & 393855,11 & 366,7 \\
\hline 36 & Brasilândia & MS & 7651684,04 & 393892,78 & 359,7 \\
\hline 37 & Brasilândia & MS & 7651721,10 & 393958,75 & 357,7 \\
\hline 1 & Itarumã & GO & 7927494,86 & 473619,00 & 491,3 \\
\hline 9 & Itarumã & GO & 7915320,98 & 462217,38 & 502,9 \\
\hline 10 & Itarumã & GO & 7915393,32 & 462203,64 & 500,7 \\
\hline 11 & Itarumã & GO & 7915474,34 & 462164,92 & 497,7 \\
\hline 14 & Itarumã & GO & 7915495,02 & 462267,80 & 497,0 \\
\hline 15 & Itarumã & GO & 7915446,58 & 462333,00 & 499,3 \\
\hline 16 & Itarumã & GO & 7915973,99 & 462638,82 & 497,0 \\
\hline 17 & Itarumã & GO & 7916009,06 & 462472,93 & 494,3 \\
\hline 18 & Itarumã & $\mathrm{GO}$ & 7916054,46 & 462376,76 & 491,6 \\
\hline
\end{tabular}

Cultura Agronômica, Ilha Solteira, v.26, n.2, p.203-216, 2017 


\begin{tabular}{llllll}
19 & Itarumã & GO & 7915310,85 & 462407,55 & 505,2 \\
20 & Itarumã & GO & 7927006,50 & 475020,88 & 484,9 \\
21 & Itarumã & GO & 7926788,59 & 474484,75 & 488,3 \\
22 & Itarumã & GO & 7926622,82 & 474631,49 & 496,9 \\
25 & Itarumã & GO & 7927728,05 & 473738,21 & 476,5 \\
27 & Itarumã & GO & 7927831,50 & 473264,87 & 491,0 \\
28 & Itarumã & GO & 7915032,02 & 462241,77 & 510,7 \\
29 & Itarumã & GO & 7914923,97 & 462212,81 & 511,5 \\
31 & Itarumã & GO & 7915105,53 & 462316,10 & 513,8 \\
\hline
\end{tabular}

Para as análises moleculares julgou-se oportuno coletar amostras foliares de mais árvores de cada população a fim de garantir o sucesso da extração do DNA, uma vez que por se tratar de uma espécie arbórea nativa o processo de extração de DNA genômico é dificultado por apresentar vários produtos inespecíficos, por esta razão, a Tabela 2 ilustra um número de amostras diferenciado da Tabela 1.

Tabela 2. Descrição das amostragens das populações de Dipteryx alata e suas localizações.

\begin{tabular}{ccclcc}
\hline População & Sigla & $\begin{array}{c}\text { Árvores } \\
\text { matrizes }\end{array}$ & \multicolumn{2}{c}{ Localização } \\
\hline Brasilândia/MS & POP-BR & 20 & $\begin{array}{l}\text { Interior de pastagens contornada por } \\
\text { plantações de eucalipto }\end{array}$ \\
Indiara/GO & $\begin{array}{c}\text { POP- } \\
\text { IND }\end{array}$ & 21 & $\begin{array}{l}\text { Fragmento ao lado da rodovia e em volta de } \\
\text { pastagens }\end{array}$ \\
Itarumã/GO & POP-ITA & 22 & \begin{tabular}{l} 
Interior de pastagens \\
\hline
\end{tabular}
\end{tabular}

\section{Métodos - Extração de DNA}

Para o estudo da variabilidade genética foram coletadas 63 amostras de folhas de matrizes de baru nas três populações. Foram utilizados tecidos foliares jovens coletados, identificados, acondicionados em sacos plásticos e mantidos em gelo até a chegada ao Laboratório de Genética de Populações e Silvicultura (LGPS), está localizado no Campus II da FEIS/UNESP, em Ilha Solteira, SP. No laboratório, as folhas foram acondicionadas em câmara fria até o momento da extração.

Para extração de DNA, cerca de $150 \mathrm{mg}$ de folhas jovens foram picotadas e colocadas em microtubos de 2,0 mL e maceradas em nitrogênio líquido com auxílio de pistilo, adicionando-se, em seguida, $800 \mu \mathrm{L}$ de tampão de extração, de acordo com método CTAB $2 \%$ (4,5\% de CTAB; EDTA - 0,5M; pH 8,0; Tris-HCl - 1M; pH 8,0; $\mathrm{NaCl} 5 \mathrm{M}, 1 \%$ de PVP-40, 0,2\% $\beta$-mercaptoetanol) proposto por Doyle e Doyle (1990) com modificações.

As amostras foram incubadas em banho-maria a $65^{\circ} \mathrm{C}$ por cerca 60 minutos, invertendo os microtubos a cada 10 minutos. Após a incubação foi realizada a desproteinização adicionando $600 \mu \mathrm{L}$ de clorofórmio-álcool isoamílico (24:1) em cada amostra, em seguida foram homogeneizadas no vortex. As amostras foram centrifugadas por

Cultura Agronômica, Ilha Solteira, v.26, n.2, p.203-216, 2017 
10 minutos à $10.000 \mathrm{rpm}$. Posteriormente, o sobrenadante foi transferido para um microtubo limpo, sendo adicionado $50 \mu \mathrm{L}$ CTAB 7\% em continuação da desproteinização.

Para precipitação do DNA, foi adicionado ao sobrenadante $500 \mu \mathrm{L}$ de isopropanol gelado, incubando-se por 2 horas em freezer a $-20^{\circ} \mathrm{C}$ e centrifugado. Para formação do pellet, os tubos foram, então, submetidos a uma centrifugação por 10 minutos a $10.000 \mathrm{rpm}$. O sobrenadante foi retirado, com cuidado, invertendo-se o microtubo em um béquer. Adicionou-se ao pellet precipitado $500 \mu \mathrm{L}$ de etanol $70 \%$ gelado, centrifugando por cinco minutos a $12.000 \mathrm{rpm}$, descartando novamente o sobrenadante (etanol). Este procedimento repetido mais uma vez e em seguida foi feita uma nova purificação utilizando o etanol absoluto gelado. Posteriormente os ácidos nucleicos foram ressuspendidos com $50 \mu \mathrm{L}$ de TE (100 mM Tris / $10 \mathrm{mM}$ EDTA) contendo $6 \mu \mathrm{L}$ de RNAse e incubando a $37^{\circ} \mathrm{C}$ em banho maria por 30 minutos e acondicionados em freezer à $-20^{\circ} \mathrm{C}$.

Para verificação da qualidade do DNA, utilizou-se um minigel de agarose 0,8\%, corado com GEL Red ${ }^{\circledR}$ em tampão TBE 1X (Tris-Boro-EDTA) por eletroforese em cuba horizontal. A quantidade do DNA foi visualizada e fotografada sob luz ultravioleta, em transiluminador Loccus Biotecnologia ${ }^{\circledR}$, modelo L-PIX-HE, esse processo foi utilizado como indicador da integridade do DNA extraído. Para o processo de avaliação da pureza foi quantificado em aparelho Nanodrop a $260 \mathrm{~nm}$, com $2 \mu \mathrm{L}$ de DNA puro.

Tabela 3. Sequências dos primers SSR descritos por Soares et al. (2012) para Dipteryx alata.

\begin{tabular}{|c|c|c|c|}
\hline Loco & Sequência do primer $\left(5^{\prime}-3^{\prime}\right)$ & $\begin{array}{l}\text { Motivo de } \\
\text { repetição }\end{array}$ & $\begin{array}{l}\text { Temperatura de } \\
\text { anelamento }\left({ }^{\circ} \mathrm{C}\right)\end{array}$ \\
\hline \multirow{2}{*}{ DaE06 } & F: TGCAGCATAAAAATTGCGAA & \multirow{2}{*}{$(\mathrm{AAAT})_{4}$} & \multirow[t]{2}{*}{60} \\
\hline & R: TTACCCAAAGCCTCAAGAA & & \\
\hline \multirow{2}{*}{ DaE12 } & F: CCTTCTATGCGCTCTCTGCT & \multirow{2}{*}{$(\mathrm{ATTTTT})_{3}$} & \multirow[t]{2}{*}{64} \\
\hline & R: TACTTCAACGCCAGCTTCCT & & \\
\hline \multirow{2}{*}{ DaE20 } & F: AATAGCAGGGCACCATTCAC & \multirow{2}{*}{$(\mathrm{AG})_{8}$} & \multirow[t]{2}{*}{$60 *$} \\
\hline & R: ACGTTTTTGCCGACATTCAT & & \\
\hline \multirow{2}{*}{ DaE34 } & F: ATCCTCTGCGTGCATTCTTT & \multirow{2}{*}{$(\mathrm{GA})_{5}$} & \multirow[t]{2}{*}{$64 *$} \\
\hline & R: CGCTTGCTGCTATTCCTTTC & & \\
\hline \multirow{2}{*}{ DaE41 } & F: GCCTCCTCCTCCGGTATCTA & \multirow{2}{*}{$(\mathrm{CA})_{5}$} & \multirow[t]{2}{*}{$66^{*}$} \\
\hline & R: CAGCAGTGGGAGTGTCAGAA & & \\
\hline \multirow{2}{*}{ DaE67 } & F: CAGCGGACCTGAGAGAAGG & \multirow{2}{*}{$(\mathrm{GATACA})_{4}$} & \multirow[t]{2}{*}{$66^{*}$} \\
\hline & R: AATTGAGGCTGATGTTTGGG & & \\
\hline \multirow{2}{*}{ DaE46 } & F: GCCTATGCGTCCTTCAGATT & \multirow{2}{*}{$(\mathrm{TTA})_{5}$} & \multirow[t]{2}{*}{56} \\
\hline & R: TTTTGCCACATGCTTCTTTG & & \\
\hline
\end{tabular}

(*) Para a amplificação do DNA de Dipteryx alata os primers DaE20, DaE34, DaE41 e DaE67 ocorreram mudanças nas temperaturas de anelamento sendo $56^{\circ}, 60^{\circ}, 60^{\circ}$ e $60^{\circ}$, respectivamente.

Fonte: Soares et al. (2012).

Cultura Agronômica, Ilha Solteira, v.26, n.2, p.203-216, 2017 
A caracterização do DNA genômico foi feita com base nos locos microssatélites que foram amplificados por PCR em um volume final de 11,5 $\mu \mathrm{L}$, usando GoTaq ${ }^{\circledR}$ Colorless Master Mix, contendo 6,0 $\mu \mathrm{L}$ de GoTaq ${ }^{\circledR}$ Colorless Master Mix (2x), 1,5 $\mu \mathrm{M}$ de primer (F e R), 2,0 $\mu \mathrm{L}$ de água nuclease free e $10 \mathrm{ng} / \mu \mathrm{L}$ de DNA. As reações de amplificação foram realizadas em termociclador marca Eppendorf, assim o programa de amplificação para todos os iniciadores constituiu-se de desnaturação inicial a $94^{\circ} \mathrm{C}$ durante $5 \mathrm{~min}$., seguido de 30 ciclos de amplificação $\left(94^{\circ} \mathrm{C}\right.$ [1 min.], $1 \mathrm{~min}$. de anelamento a uma temperatura específica de cada primer, $72^{\circ} \mathrm{C}$ de alongamento da cadeia por $1 \mathrm{~min}$.) e um alongamento final a $72^{\circ} \mathrm{C}$ por $12 \mathrm{~min}$. As amplificações foram realizadas usando um conjunto de primers (Tabela 3 e 4 ).

Para maior precisão de genotipagens, foi utilizado um fragmentador automático, AdvanCE ${ }^{\mathrm{TM}}$ FS96 System. Este equipamento utiliza um sistema de eletroforese capilar e não necessita de primers fluorescentes marcados. É um equipamento com a maior sensibilidade, rapidez na análise e possui alta resolução de separação dos fragmentos. Para realização da genotipagem, as PCR foram diluídas em TE $(2,0 \mu \mathrm{L}$ da PCR $+20 \mu \mathrm{L}$ de TE), com duração de 90 minutos para as 60 amostras.

As leituras dos eletroferogramas feitas pelo fragmentador automático foram analisadas no programa PROSize ${ }^{\circledR 2.0 .}$

Tabela 4. Sequências dos primers SSR citado por Tarazi et al. (2010) para Dipteryx alata.

\begin{tabular}{ccc}
\hline \multirow{2}{*}{ Loco } & Sequência do primer $\left(5^{\prime}-3^{\prime}\right)$ & $\begin{array}{c}\text { Temperatura de anelamento } \\
\left({ }^{\circ} \mathrm{C}\right)\end{array}$ \\
\hline \multirow{2}{*}{ Do06 } & $\begin{array}{c}\text { F: AGCGGTGAAAAGACCATAGC } \\
\text { R: CCAACGATAAGATTCCTCCA }\end{array}$ & 54 \\
\hline \multirow{2}{*}{ Do08 } & $\begin{array}{c}\text { F: AGATCAGCGGACAAAGGTCT } \\
\text { R: GTAATGTTGTGCACTCTTG }\end{array}$ & 58 \\
\hline \multirow{2}{*}{ Do17 } & $\begin{array}{c}\text { F: GTTGCTGTCGGTTCTCCATA } \\
\text { R: CCAAGGACGCTGTGCTCTAC }\end{array}$ & 56 \\
\hline \multirow{2}{*}{ Do24 } & $\begin{array}{c}\text { F: AACGCAGGATCTAGCCAAAA } \\
\text { R: CTTCTCGCTGTTGTGCACTC }\end{array}$ \\
\hline \multirow{2}{*}{ Do25 } & $\begin{array}{c}\text { F: AAATGCAAAACGGAAGAGGA } \\
\text { R CCCCTGAAGGAGACTTCGAT }\end{array}$ \\
\hline \multirow{2}{*}{ Do35 } & $\begin{array}{c}\text { F: CAACCAAAGCAAACAAAGCA } \\
\text { R: GCTGAGAAAGGGGAATGCAG }\end{array}$ \\
\hline
\end{tabular}

Fonte: Tarazi et al. (2010).

\section{Diversidade genética}

A diversidade genética interpopulacional foi caracterizada pela riqueza alélica $(\hat{R})$, calculada por rarefação, heterozigosidade observada $\left(\hat{H}_{o}\right)$ e heterozigosidade esperada segundo as proporções do equilíbrio de Hardy-Weinberg $\left(\hat{H}_{e}\right)$. A presença de endogamia foi estimada usando o índice de fixação $(\hat{F})$ e sua significância estatística foi estimada Cultura Agronômica, Ilha Solteira, v.26, n.2, p.203-216, 2017 
utilizando permutação de alelos entre indivíduos. Os índices de diversidade genética, o índice de fixação e permutação foi calculado usando o programa FSTAT (GOUDET, 1995).

\section{RESULTADOS E DISCUSSÃO}

No presente estudo os 12 locos microssatélites analisados foram polimórficos (Tabela 5). É possível observar que os valores médios dos parâmetros da diversidade genética entre as três populações são semelhantes. Em termos médios do número total de alelos $(k=61)$ pode ser considerado baixo em relação à média encontrada nas 13 espécies nativas arbóreas $(k=87)$ apresentadas na Tabela 6 . Esta média é baixa devido ao número de indivíduos amostrados nesses trabalhos ser muito maior que os do presente estudo, sendo esperado que o valor de $k$ fosse maior. Tanto a heterozigosidade observada $\left(\hat{H}_{o}\right)$ como a heterozigosidade esperada $\left(H_{e}\right)$ apresentaram comportamento semelhante ao $k$, sendo a $\hat{H}_{o}$ apenas superior à espécie Theobroma grandiflorum e a $H_{e}$ sendo superior a Araucaria angustifólia, Hymenaea stignocarpa, Theobroma cacao e Theobroma grandiflorum. $\mathrm{O}$ interessante foi que essas 13 espécies estudadas estão em áreas de fragmento ou pastagens sujeitas à perturbação antrópica como as três populações do presente estudo, assim, era esperado que os níveis de diversidade fossem semelhantes. Moraes et al. (2007) inferem que alto estado de fragmentação e o pequeno tamanho das populações pode ser a causa da baixa diversidade genética, mas para responder esta questão seria necessário pelo menos comparar os resultados com outros obtidos a partir de populações grandes e contínuas da mesma espécie. Entretanto, na literatura essas informações sobre a Dipteryx alata são limitadas.

As três populações de Dipteryx alata estão em condições diferenciadas no ambiente, a POP-BR está localizada no interior de pastagens e contornada por plantações de eucalipto, a POP-IND está em um fragmento ao lado da rodovia e em volta de pastagens e a POP-ITA está na pastagem, ou seja, a POP-ITA está menos propensa a visita dos polinizadores (abelhas) do que a POP-IND. Oliveira e Sigrist (2008) observaram que a Dipteryx alata apresenta auto-incompatibilidade, ou seja, a espécie não tolera autofecundação. Isso mostra que a diversidade genética da espécie deveria ser muito maior que os resultados apresentados no presente trabalho, pois as populações deveriam estar em intenso fluxo gênico entre os indivíduos, mas não foi o caso, ou seja, nas três áreas estudadas a densidade do polinizador (abelha) é muito baixa, e isso está interferindo no sistema de reprodução, fluxo gênico e diversidade genética.

Um alto e significativo índice de fixação $(\hat{F})$ foi detectado nas árvores adultas das três populações de Dipteryx alata, sugerindo desvios das proporções de equilíbrio de HardyWeinberg. Altos índices de fixação podem ocorrer devido à presença de alelos nulos, autofecundação, cruzamentos endogâmicos e devido ao efeito Wahlund, causado pela presença de estruturação das populações. No presente caso, deve-se descartar a presença de alelos nulos, pois os primers foram desenvolvidos especificamente para a espécie e a

Cultura Agronômica, Ilha Solteira, v.26, n.2, p.203-216, 2017 
autofecundação, pois a espécie apresenta auto-incompatibilidade. A endogamia está presente na maior parte das populações naturais que nada mais é do que uma consequência das ações antrópicas, como pode ser observado na Tabela 6 .

Os estudos utilizando marcadores moleculares microssatélites tem se mostrado vantajosos, atingindo seus propósitos de fornecer subsídios para programas de conservação e manejo, permitindo o uso sustentável de recursos (VIANNA, 2015). Nesse contexto, para as pesquisas futuras, seria oportuno aumentar o número de amostras de cada população, coletar sementes e estudar a geração descendente, a fim de ter maior entendimento nos padrões do sistema de reprodução e fluxo gênico para assim, poder estimar e orientar uma coleta de sementes adequada visando à conservação genética ex situ e restauração ambiental. 
Tabela 5. Diversidade genética, índice de fixação $(\hat{F})$ em locos microssatélites de árvores adultas de Dipteryx alata. $n$ é o tamanho amostral; $k$ é o número total de alelos; $\hat{R}$ é a riqueza alélica para os indivíduos genotipados nos 12 locos microssatélites; $\hat{H}_{o}$ é a heterozigosidade observada; $H_{e}$ é a heterozigosidade esperada.

\begin{tabular}{|c|c|c|c|c|c|c|c|c|c|c|c|c|c|c|c|}
\hline \multirow{2}{*}{ Loco } & $k$ & $\hat{R}$ & $\hat{H}_{o}$ & $\hat{H}_{e}$ & $\hat{F}$ & $k$ & $\hat{R}$ & $\hat{H}_{o}$ & $\hat{H}_{e}$ & $\hat{F}$ & $k$ & $\hat{R}$ & $\hat{H}_{o}$ & $\hat{H}_{e}$ & $\hat{F}$ \\
\hline & \multicolumn{5}{|c|}{ Brasilândia $(n=20)$} & \multicolumn{5}{|c|}{ Itarumã $(n=21)$} & \multicolumn{5}{|c|}{ Indiara $(n=22)$} \\
\hline DaE12 & 4,0 & 4,0 & 0,100 & 0,603 & $0,834 *$ & 3,0 & 3,0 & 0,000 & 0,329 & $1,000 *$ & 3,0 & 3,0 & 0,00 & 0,667 & $1,000^{*}$ \\
\hline DaE20 & 8,0 & 8,0 & 0,499 & 0,709 & $0,295^{*}$ & 5,0 & 5,0 & 0,455 & 0,723 & $0,371 *$ & 8,0 & 7,9 & 0,285 & 0,825 & $0,654 *$ \\
\hline DaE46 & 4,0 & 4,0 & 0,050 & 0,571 & $0,912 *$ & 3,0 & 3,0 & 0,045 & 0,361 & $0,874 *$ & 3,0 & 3,0 & 0,047 & 0,676 & $0,930 *$ \\
\hline DaE67 & 4,0 & 4,0 & 0,899 & 0,646 & $-0,393$ & 3,0 & 3,0 & 0,772 & 0,619 & $-0,248$ & 6,0 & 5,9 & 0,809 & 0,713 & $-0,135$ \\
\hline DaE34 & 3,0 & 3,0 & 0,200 & 0,422 & $0,526^{*}$ & 4,0 & 3,9 & 0,272 & 0,453 & & 5,0 & 4,9 & 0,476 & 0,711 & $0,330 *$ \\
\hline DaE41 & 4,0 & 4,0 & 0,500 & 0,562 & $0,110^{*}$ & 4,0 & 3,9 & 0,227 & 0,563 & $0,596^{*}$ & 6,0 & 5,9 & 0,381 & 0,706 & $0,460 *$ \\
\hline DaE63 & 3,0 & 3,0 & 0,049 & 0,553 & $0,910^{*}$ & 8,0 & 7,9 & 0,227 & 0,847 & $0,732 *$ & 5,0 & 4,9 & 0,143 & 0,626 & $0,772 *$ \\
\hline DaE06 & 3,0 & 3,0 & 0,299 & 0,408 & $0,265^{*}$ & 3,0 & 3,0 & 0,000 & 0,455 & $1,000 *$ & 2,0 & 2,0 & 0,00 & 0,324 & $1,000 *$ \\
\hline DaE08 & 9,0 & 9,0 & 0,499 & 0,868 & $0,424 *$ & 7,0 & 6,9 & 0,273 & 0,749 & $0,636^{*}$ & 12,0 & 11,7 & 0,714 & 0,871 & $0,180^{*}$ \\
\hline DaE35 & 7,0 & 7,0 & 0,249 & 0,733 & $0,659 *$ & 9,0 & 8,7 & 0,500 & 0,790 & $0,367 *$ & 9,0 & 8,8 & 0,476 & 0,756 & $0,370 *$ \\
\hline DaE24 & 7,0 & 7,0 & 0,499 & 0,797 & $0,373^{*}$ & 7,0 & 6,9 & 0,500 & 0,855 & $0,415^{*}$ & 5,0 & 5,0 & 0,667 & 0,767 & $0,130^{*}$ \\
\hline DaE25 & 4,0 & 4,0 & 0,650 & 0,757 & $0,141^{*}$ & 5,0 & 4,9 & 0,682 & 0,673 & $-0,013$ & 5,0 & 4,9 & 0,380 & 0,527 & $0,278^{*}$ \\
\hline Média & 5,0 & 5,0 & 0,375 & 0,636 & $0,421 *$ & 5,08 & 5,03 & 0,329 & 0,618 & $0,511 *$ & 5,7 & 5,7 & 0,365 & 0,681 & $0,497 *$ \\
\hline DP & 2,13 & 2,13 & 0,262 & 0,143 & $0,381 *$ & 2,15 & 2,09 & 0,255 & 0,185 & $0,381 *$ & 2,80 & 2,7 & 0,279 & 0,144 & $0,372 *$ \\
\hline Total & 60 & - & - & - & - & 61 & - & - & - & - & 69 & - & - & - & - \\
\hline
\end{tabular}

$* \mathrm{P}<0.05$. DP e o desvio padrão. 
Tabela 6. Parâmetros genéticos estimados para espécies arbóreas tropicais com base em locos microssatélites: $n$ é o tamanho amostral; $k$ é o número total de alelos; $\hat{H}_{o}$ é a heterozigosidade observada; $H_{e}$ é a heterozigosidade esperada e $\hat{F}$ é o índice de fixação.

\begin{tabular}{lcccccc}
\hline \multicolumn{1}{c}{ Espécies } & $n$ & $k$ & $H_{o}$ & $H_{e}$ & $F$ & Referências \\
\hline Araucaria angustifolia & 108 & 62 & 0,551 & 0,585 & 0,058 & Bittencourt e Sebbenn (2008) \\
Bagassa guianensis & 488 & 71 & 0,626 & 0,693 & 0,097 & Arruda et al. $(2015)$ \\
Cariniana legalis & 65 & 100 & 0,810 & 0,860 & 0,060 & Tambarussi et al. $(2016)$ \\
Copaifera langsdorffii & 112 & 186 & 0,757 & 0,893 & 0,152 & Sebbenn et al. $(2011)$ \\
Dinizia excelsa & 553 & 91 & 0,651 & 0,728 & - & Dick et al. $(2003)$ \\
Hymenaea courbaril & 64 & 79 & 0,607 & 0,813 & 0,259 & Feres et al. $(2009)$ \\
Hymenaea stignocarpa & 42 & 70 & 0,367 & 0,623 & 0,411 & Moraes et al. $(2007)$ \\
Manilkara huberi & 289 & 124 & 0,706 & 0,856 & 0,175 & Azevedo et al. $(2007)$ \\
Myracrodruon urundeuva & 467 & 60 & 0,691 & 0,686 & $-0,018$ & Gaino et al. $(2010)$ \\
Symphonia globulifera & 161 & 144 & 0,783 & 0,907 & 0,137 & Carneiro et al. $(2009)$ \\
Tabebuia roseo-alba & 22 & 52 & 0,635 & 0,761 & 0,167 & Feres et al. $(2012)$ \\
Theobroma cacao & 127 & 26 & 0,496 & 0,477 & $-0,041$ & Silva et al. $(2011)$ \\
Theobroma grandiflorum & 40 & 71 & 0,355 & 0,419 & 0,192 & Alves et al. $(2007)$ \\
\hline \multicolumn{1}{c}{ Média } & & 87 & 0,618 & 0,715 & & \\
\hline
\end{tabular}

\section{CONCLUSÃO}

As três populações de Dipteryx alata apresentaram diversidade genética semelhante, porém moderada e forte endogamia. A presença dessa variabilidade genética é fundamental para a sobrevivência das populações ao longo das gerações, ressaltando a importância de estudos genéticos mais aprofundados para melhor entendimento do comportamento reprodutivo da espécie para poder, assim, estabelecer estratégias adequadas de conservação in situ e ex situ da espécie.

\section{REFERÊNCIAS BIBLIOGRÁFICAS}

ALMEIDA, S. P.; PROENÇA, C. E. B.; SANO, S. M.; RIBEIRO, J. F. Cerrado: espécies vegetais úteis. Planaltina: EMBRAPA-CPAC, 1998. 464 p.

ALVES, R. M.; SEBBENN, A. M.; ARTERO, A. S.; CLEMENT, C.; FIGUEIRA, A. High levels of genetic divergence and inbreeding in populations of cupuassu (Theobroma grandiflorum). Tree Genetics \& Genomes, St. Louis, v. 3, n. 4, p.289-298, 2007.

ANTI, A. B. Caracterização de germoplasma de soja e de feijão através de eletroforese de isoenzimas da semente. Bragantia, Campinas, v. 59, n. 2, p.139-42, 2000.

ARRUDA, C. C. B.; SILVA, M. B.; SEBBENN, A. M.; KANASHIRO, M.; LEMES, M. R.; GRIBEL, R. Mating system and genetic diversity of progenies before and after logging:

Cultura Agronômica, Ilha Solteira, v.26, n.2, p.203-216, 2017 
a case study of Bagassa guianensis (Moraceae), a low-density dioecious tree of the Amazonian forest. Tree Genetics \& Genomes, St. Louis, v. 11, n. 3, p.2-9, 2015.

AZEVEDO, V. C. R.; KANASHIRO, M.; CIAMPI, A. Y.; GRATTAPAGLIA, D. Genetic Structure and Mating System of Manilkara huberi (Ducke) A. Chev., a Heavily Logged Amazonian Timber Species. Journal of Heredity, Washington, v. 98, n. 7, p.646-654, 2007.

BITTENCOURT, J. V. M.; SEBBENN, A. M. Pollen movement within a continuous forest of wind-pollinated Araucaria angustifolia, inferred from paternity and TWOGENER analysis. Conservation Genetics, Amsterdam, v. 9, n. 4, p.855-868, 2008.

CARNEIRO, F. S.; DEGEN, B.; KANASHIRO, M.; LACERDA, A. E. B. L.; SEBBENN, A. M. High levels of pollen dispersal detected through paternity analysis from a continuous Symphonia globulifera population in the Brazilian Amazon. Forest Ecology and Management, Amsterdam, v. 258, n. 7, p.1260-1266, 2009.

CARVALHO, P. E. R. Espécies Arbóreas Brasileiras, Brasília: Embrapa Informação Tecnológica, v. 1, 2003. 1039 p.

DICK, C. W.; ETCHELECU, G.; AUSTERLITZ, F. Pollen dispersal of tropical trees (Dinizia excelsa: Fabaceae) by native insects and African honeybees in pristine and fragmented Amazonian rainforest. Molecular Ecology, New York, v. 12, n. 3, p.753-764, 2003.

DOYLE, J. J.; DOYLE, J. L. Isolation of plant DNA from fresh tissue. Focus, Rockville, Maryland, v. 12, n. 1, p.13-15, 1990.

FALEIRO, F. G. Marcadores genético-moleculares aplicados a programas de conservação e uso de recursos genéticos. Planaltina: Embrapa Cerrados, 2007. 102 p.

FALEIRO, F. G. Aplicações de marcadores moleculares como ferramenta auxiliar em programas de conservação, caracterização e uso de germoplasma e melhoramento genético vegetal. In: FALEIRO, F. G.; ANDRADE, S. R. M.; REIS JÚNIOR, F. B.; (Org.). Biotecnologia: estado da arte e aplicações na agropecuária. Planaltina, DF: Embrapa Cerrados, 2011. cap. 3, p. 55-118.

FERES, J. M.; GUIDUGLI, M. C.; MESTRINER, M. A.; SEBBENN, A. M.; CIAMPI, A. Y.; ALZATE-MARIN, A. L. Microsatellite diversity and effective population size in a germplasm bank of Hymenaea courbaril var. stilbocarpa (Leguminosae), an endangered tropical tree: recommendations for conservation. Genetic Resources and Crop Evolution, Dordrecht, v. 56, n. 6, p. 797-807, 2009.

FERES, J. M.; SEBBENN, A. M.; GUIDUGLI, M. C.; MESTRINER, M. A.; MORAES, M. L. T.; ALZATE-MARIN, A. L. Mating system parameters at hierarchical levels of fruits, individuals and populations in the Brazilian insect-pollinated tropical tree, Tabebuia roseoalba (Bignoniaceae). Conservation Genetics, Arlington, v. 13, n. 2, p.393-405, 2012.

Cultura Agronômica, Ilha Solteira, v.26, n.2, p.203-216, 2017 
FERREIRA, M. E.; GRATTAPAGLIA, D. Introdução ao uso de marcadores moleculares em análise genética. 3. ed. Brasília: Embrapa/Cenargen, 1998. 220 p.

GAINO, A. P. S. C.; SILVA, A. M.; MORAES, M. A.; ALVES, P. F.; MORAES, M. L. T.; FREITAS, M. L. M.; SEBBENN, A. M. Understanding the effects of isolation on seed and pollen flow, spatial genetic structure and effective population size of the dioecious tropical tree species Myracrodruon urundeuva. Conservation Genetics, Arlington, v. 11, n. 5. p.1631-1643, 2010.

GOUDET, J. Fstat. (Version 2.9.3.2.): a computer program to calculate F-statistics. Journal of Heredity, Edinburg, v. 86, n. 6, p.485-486, 1995.

GOLDSTEIN, D. B.; SCHOLOTTER, C. Microsatellites: Evolution and Aplications. New York: Oxford University Press, 1999. 343 p.

HOPKIN, M. Brazilian savannah 'will disappear by 2030'. Nature, 2004. Disponível em:http://nature.com/News/2004/040720/full/news040719-6.html. Acesso em: 20 fev 2017.

MORAES, M. L. T.; KAGEYAMA, P. Y.; SEBBENN, A. M. Sistema de reprodução em pequenas populações fragmentadas e em árvores isoladas de Hymenaea stigonocarpa. Scientia Forestalis, Piracicaba, v. 35, n. 74, p.75-86, 2007.

OLIVEIRA, M. I. B.; SIGRIST, M. R. Fenologia reprodutiva, polinização e reprodução de Dipteryx alata Vogel (Leguminosae-Papilionoideae) em Mato Grosso do Sul, Brasil. Revista Brasileira de Botânica, São Paulo, v. 31, n. 2, p.195-207, 2008.

PEREIRA, A. V.; PEREIRA, E. B. C.; JUNQUEIRA, N. T. V. Propagação e domesticação de plantas nativas do cerrado com potencial econômico. Horticultura Brasileira, Brasília, v. 19, n. 2, 2001. Suplemento CD-ROM.

POTT, A.; POTT, V. J. Espécies de fragmentos florestais em Mato Grosso do Sul. In: COSTA, R. B. (ed.). Fragmentação Florestal e Alternativas de Desenvolvimento Rural na Região Centro-Oeste. Campo Grande: UCDB. 2003. cap. 2 , p.26-52.

RIBEIRO, J. F.; SANO, S. M.; BRITO, M. A.; FONSECA, C. E. L.. Baru (Dipteryx alata Vog). Jaboticabal: Funep, 2000. 41 p. (Série Frutas Nativas, 10).

ROBINSON, I. P. Aloenzimas na genética de populações de plantas. In: ALFENAS, A. C. (Ed.). Eletroforese de isoenzimas e proteínas afins: fundamentos e aplicações em plantas e microrganismos. Viçosa, MG: UFV, 1998. cap. 3, p. 329-380.

SANO, S. M.; RIBEIRO, J. F.; BRITO, M. A. Baru: biologia e uso. Planaltina: Embrapa Cerrados, 2004. 52 p. (Embrapa Cerrados. Documentos, 116)

SANO, S. M.; BRITO, M. A.; RIBEIRO, J. F. Baru. In: VIEIRA, R. F.; AGOSTINICOSTA, T. S.; SILVA, D. B.; SANO, S. M.; FERREIRA, F. R. (Eds). Frutas nativas da região Centro-Oeste do Brasil. Brasília, DF: Embrapa Informação Tecnológica, 2010. cap. 5, p. 76-99.

Cultura Agronômica, Ilha Solteira, v.26, n.2, p.203-216, 2017 
SCHOLOTTERER, C. Evolutionary dynamics of microsatellite DNA. Chromossoma, Berlin, v. 109, n. 8, p.365-371, 2000.

SEBBENN, A. M.; CARVAlHO, A. C. M.; FREITAS, M. L. M.; MORAES, S. M. B.; GAINO, A. P. S. C.; JOLIVET, C.; MORAES, M. L. T. Low levels of realized seed and pollen gene flow and strong spatial genetic structure in a small, isolated and fragmented population of the tropical tree Copaifera langsdorffii Desf. Heredity, Washington, v. 106, n. 1, p.134-145, 2011.

SILVA, C. R. S.; ALBUQUERQUE, P. S. B.; ERVEDOSA, F. R.; MOTA, J. W. S.; SEBBENN, A.M. Understanding the genetic diversity, spatial genetic structure and mating system at the hierarchical levels of fruits and individuals of a continuous Theobroma cacao population from the Brazilian Amazon. Heredity, Washington, v. 106, n. 1, p.973-985, 2011.

SOARES, T. N.; MELO, D. B.; RESENDE, L. V.; VIANELLO, R. P.; CHAVES, L. J.; COLLEVATTI, R. G.; TELLES, M. P. C. Development of microsatellite markers for the neotropical tree species Dipteryx alata (Fabaceae). American Journal of Botany, Columbus, v. 99, n. 2, p.72-73, 2012.

TAMBARUSSI, E. V.; BOSHIER, D. H.; VENCOVSKY, R.; FREITAS, M. L. M.; DIDIO, O. J.; SEBBENN, A. M. Several Small: How Inbreeding Affects Conservation of Cariniana legalis Mart. Kuntze (Lecythidaceae) the Brazilian Atlantic Forest's Largest Tree. International Forestry Review, Salt Lake City - USA, v. 18, n. 4, p.502-510, 2016.

TARAZI, R.; MORENO, M.A.; GANDARA, F.B.; FERRAZ, E.M.; MORAES, M.L.T.; VINSON, C.C.; CIAMPI, A. Y.; VENCOVSKY, R.; KAGEYAMA, P.Y. High levels of genetic differentiation and selfing in the Brazilian cerrado fruit tree Dipteryx alata Vog. (Fabaceae). Genetics and Molecular Biology, Ribeirão Preto, v. 1, n. 33, p.78-85, 2010.

VIANNA, L. S. Caracterização da diversidade genética de duas populações naturais de Vochysia bifalcata Warm no Parque Nacional do Caparaó/ES. Nucleus, Ituverava, v. 12, n. 1, p.173-180, 2015. 